\title{
Role of Transient Characteristics in Fish Trajectory Modeling
}

\author{
Gao Zhu ${ }^{1,2,3, * \mathbb{C}, \text { Zuhao Zhou }^{2} \text { and Helge I Andersson }}{ }^{3}$ \\ 1 School of Transportation and Civil Engineering, Nantong University, Nantong 226019, China \\ 2 State Key Laboratory of Simulation and Regulation of Water Cycle in River Basin, China Institute of Water \\ Resources and Hydropower Research, Beijing 100038, China; zhzh@iwhr.com \\ 3 Department of Energy and Process Engineering, Norwegian University of Science and Technology, \\ 7491 Trondheim, Norway; helge.i.andersson@ntnu.no \\ * Correspondence: zhu.gao@outlook.com
}

Received: 22 July 2020; Accepted: 18 August 2020; Published: 20 August 2020

\begin{abstract}
In this experiment, we analyzed live fish (silver carp) trajectories recorded in an experimental vertical-slot fishway. Combined with a numerical simulation, we demonstrated that randomness shown in fish trajectories might not merely be attributed to the fish's random choices in its swimming, but could also be a consequence of adaption to the bulk unsteady turbulent flow structures. Simple superposition of a fish trajectory on the time-averaged flow field obtained either by interpolating on discrete point measurements or numerical simulation data is not an ideal method for description of fish movement. How to model the fish paths in transient flow and the necessity of simultaneous recording of the flow field and the fish locomotion are challenging topics. We also discussed the possible integration of currently existing methods to promote the development of fish trajectory modeling.
\end{abstract}

Keywords: fishway; trajectory; CFD; measurement; modeling

\section{Introduction}

River fragmentation by dams and weirs is heavily responsible for the dramatic decline in the range and abundance of freshwater fish, making fisheries development unsustainable. In order to minimize such consequences, fishways are designed in a watercourse for mitigating the fragmentation and keeping the sustainability of the river systems and the fisheries. One crucial problem worth discussing is how to solve the coupling between the complex unsteady flow field around the fish and the response made by fish during the fish pass, for which live fish tracing is an effective method. As Lacey et al. [1] proposed, relating the quantitative observational data on spatial fish positions to their preference is the simplest level to start. Silva et al. [2], Goettel et al. [3], and Tan et al. [4] superposed the fish trajectories on the mean flow field in their studies. They made statistics among the hydraulic variables and the residence times or appearance frequency for the target fish. Hence, the "water preferences" of a target fish can be found for given hydraulic conditions. For later usage we refer to this approach of superposition of the fish path on time-averaged flow fields as Method I.

However, the flow in fishways is essentially a turbulent flow, which is comprised of unsteady eddies of different sizes or length-scales. The existence of large eddies or coherent flow structures implies that hydraulic variables at adjacent points possess close correlations, which are also dynamically changing with time. In Method I, the prominent features of the contours of specific hydraulic parameters are time-averaged at spatial points. During the averaging process, the vital linkage between hydraulic variables at relevant space points is ignored, and replaced by the turbulence intensity or turbulence kinetic energy. This represents only the velocity fluctuations at each isolated position and the information of the vortex structures is accordingly lost. 
In contrast to Method I, the other kind of approach, referred to as Method II herein, was used in the works carried out by Liao et al. [5,6], Tritico \& Cotel [7], and Liao \& Akanyeti [8], and describes the fish movement with the temporal vortical structures in the flow. Liao et al. [6] pointed out that fish tend to exploit vortices to decrease muscle activity. Therefore, if the vortical structures are random in a turbulent flow, fish will actively utilize the random eddies to assist their swimming. Naturally, their movement reflects the randomness. In other words, randomness in fish locomotion may be partially explained as an adaption consequence of velocity fluctuations, which could not merely be interpreted as a fundamental feature of animal choices. This new perspective leads us to reconsider our method used in fish trajectory modeling, as well as the concept of "water preferences". In our opinion, "water preferences" seems not to be a feature at a fixed point in space, but a series of continuously changing flow structures, which is better termed as "hydraulic stimuli".

Besides the experimental methods, a Computational Fluid Dynamics (CFD) technique often appears as a complementary tool to understand flow field details at any interested time and locations over variable scales of view from microscopic to macroscopic. The Lagrangian Individual-Based Model (IBM) combined with an Eulerian CFD-model is an emerging method in fish-path modeling [9-18]. Based on Lagrangian tracking of individual virtual fish, this kind of method evaluates the fishway design by calculating the passage ratios of virtual migratory fish. However, proper modeling of the response made by fish to their surrounding hydraulic stimuli is an unavoidable problem in the applications of CFD tools, and reliable experimental results are a prerequisite.

In this paper, by experimenting with an experimental fishway with live fish (silver carp) as well as a CFD simulation, we demonstrate the strengths and weaknesses of Method I, Method II, and the CFD technique in a descriptive way. The silver carp (Hypophthalmichthys molitrix) is a species of freshwater cyprinid fish, one of the most well-known commercial fish in China [19]. This is a typical potamodromous fish and has regular migratory activities in spawning and nursery periods. The species is currently classified as near-threatened in its original range, as its habitat and reproductive behaviour are heavily impacted by the construction of dams. No matter from fish conservation, economic values, or the convenience of access, this fish species is an ideal research objective for this study.

The objective of this study is threefold. Firstly, to demonstrate that randomness shown in fish trajectories might not merely be attributed to a fish's random choices in its swimming, but could also be a consequence of adaption to the bulk unsteady turbulent flow structures. Secondly, to invoke researchers to evaluate the effectiveness and practicability of the two typical methods used in fish behavior studies, i.e., superposing a fish trajectory on the time-averaged flow field, and simultaneous measurements of fish movement and the flow field around them. Thirdly, the internal hydraulic links between the three methods and a proposed integrative framework of combining them are discussed, which renders a new perspective for future experimental and numerical studies in fishway science.

\section{Material and Methods}

\subsection{Experimental Setup}

The experiments were conducted in an indoor Vertical Slot Fishway (VSF) at the Engineering Research Center of Eco-Environment in the Three Gorges reservoir region, Yichang (China). The major facility was $7 \mathrm{~m}$ long, $0.5 \mathrm{~m}$ wide, and $0.7 \mathrm{~m}$ high, as shown in Figure 1 . 


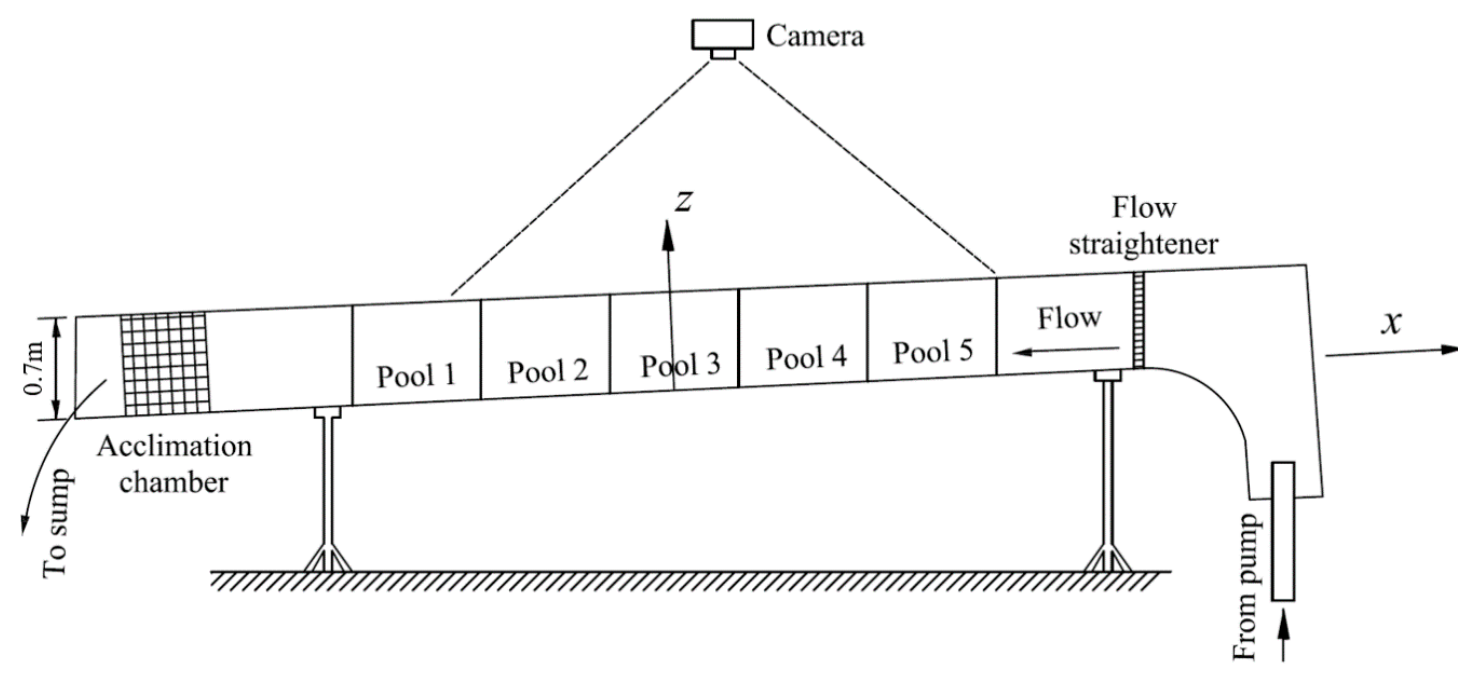

(a)

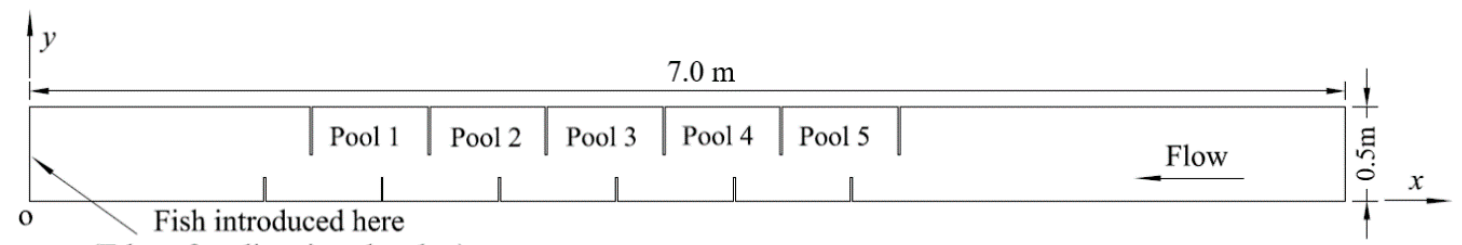

(Edge of acclimation chamber)

(b)

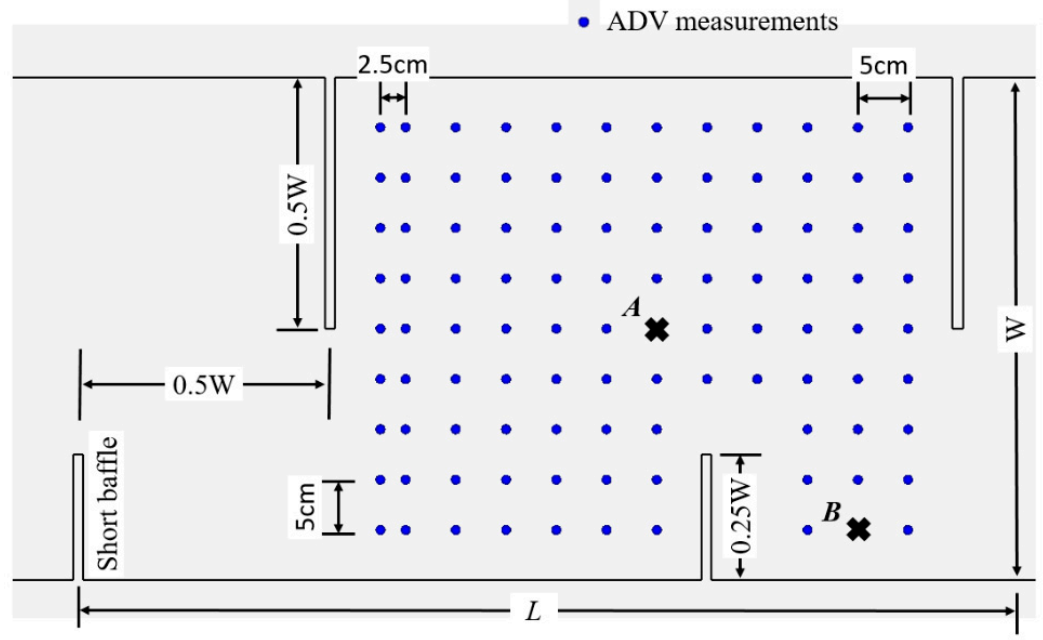

(c)

Figure 1. Schematics of experimental set-up: (a) side view; (b) plane view; (c) details of pool geometry $(L=0.625 \mathrm{~m}, W=0.5 \mathrm{~m})$ and Acoustic Doppler Velocimeter (ADV) measurement grid distribution in a plane parallel to the flume bottom at $z=9 \mathrm{~cm}$ in pool 3. Points $A$ and $B$ are marked with the symbol $\boldsymbol{*}$, as an example, where transient velocity characteristics will be described in Section Point Velocity. (Dimensions are not to scale).

The fishway consisted of seven pools divided by Polyethylene hard boards; the uppermost and the lowest pools are not labeled. The middle five pools, with identical geometry and sizes, were the test sections. The fishway was set at a slope of $1 \%$. Baffles were always vertical, despite the slope in the fishway model. The flume was connected to a head tank of the same width with a streamlined bottom and a flow straightener net to smooth the entrance flow. A pump was used to supply the head tank from the laboratory sump. The flow rate was measured by a magnetic flowmeter installed in the 
supply pipe and controlled by a valve. The fishway also encompassed an acclimation chamber at the downstream end of the channel, which was created by installing two fine mesh screens $0.5 \mathrm{~m}$ apart, thereby preventing fish from entering the channel before the experiments began. The water used in the experiments was drawn from the domestic water supply, recirculated through the laboratory pumping system for at least two weeks before the tests, and checked for temperature, $\mathrm{pH}$, and dissolved oxygen at the beginning and the end of experiments [2]. The water surface levels were measured using graduated scales placed on the sidewall of the pool, in the vicinity of the cross-walls and the middle point of the pool. The water level within the structure was regulated by a slot gate at the downstream end of the fishway to obtain a "uniform flow", the definition of which is that the mean flow depth in a pool is the same for all the pools, as suggested by Rajaratnam et al. [20]. Table 1 provides the primary details of the experiments. In a preliminary test, we observed that the fish were swimming almost in a plane parallel to the bottom at a distance of $0.3 h_{0}$ (i.e., $9 \mathrm{~cm}$ from the fishway bottom, $h_{0}$ is the water depth in the fishway). Hence, 102 sample points were measured in that plane, as shown in Figure 1c.

Table 1. Parameters of the experiments.

\begin{tabular}{ccccc}
\hline $\begin{array}{c}S \\
(\text { deg.) }\end{array}$ & $\begin{array}{c}Q \\
\left(\mathbf{m}^{3} / \mathbf{s}\right)\end{array}$ & $\begin{array}{c}\text { Velocity Measured in the Plane with z } \\
(\mathbf{c m})\end{array}$ & $\begin{array}{c}\text { ADV Sampling Time } \\
(\mathbf{s})\end{array}$ & $\begin{array}{c}\text { Water Depth } \\
(\mathbf{m m})\end{array}$ \\
\hline 1 & 0.0135 & 9 & 30 & 30 \\
\hline
\end{tabular}

Detailed instantaneous velocity measurements were conducted with a SonTek $16 \mathrm{MHz}$ Micro ADV. The advantage of using this device relies on its ability to adequately measure the three-dimensional velocity components of flowing water [2]. Velocity measurements were recorded at $50 \mathrm{~Hz}$ over a sampling period of $30 \mathrm{~s}$ in each point of the measurement grid. In a post-processing phase, ADV measurements were filtered with WinADV (release 2.031) software to remove samples with low correlation scores or signal-to-noise ratios.

\subsection{Experimental Fish}

All experimental silver carps (with a total length of $11.49 \mathrm{~cm} \pm 0.63 \mathrm{~cm}$ and total weight of $20.74 \mathrm{~g} \pm 8.64 \mathrm{~g}$ ) were supplied by Yidu hatchery, Yichang city, China. Before fish were used in the experiments, they were held for at least three days in $3000 \mathrm{~L}$ circular tanks at water temperatures of $19-21^{\circ} \mathrm{C}$, with additional air supply to maintain dissolved oxygen at $\geq 6.0 \mathrm{mgL}^{-1}$. Every two days, $30 \%$ of the water in the tanks was replaced. Fish excrement and uneaten food were removed daily. Test fish were unfed for $24 \mathrm{~h}$ before the tests [21]. A total of 30 age-0 silver carps were individually tested to avoid confounding schooling effects. Each fish was used only one time. At the beginning of each experiment, the fish were held in the downstream acclimation chamber for $15 \mathrm{~min}$. In the acclimation chamber, the fish were exposed to the freestream velocity in the flume. After this period, the screens were removed, and the fish were allowed to explore the fishway autonomously.

\subsection{Fish Tracking}

Fish movements were recorded in each trial using a video recording system, which was mainly composed of one 25 fps digital video camera (DS-2CD3345-I, Hikvision Corporation, Hangzhou, China), a video recorder (DS-7808N-K1/C, Hikvision Corporation), and a computer. The camera was suspended above the flume by a specific stand with an adjustable height. The height of the camera was selected to capture continuous clear images of the fish swimming through from Pool 2 to Pool 5. Pool 1 was not considered due to the limited shot scope of the camera. A reference grid containing 25 cells was attached to the bottom of the five pools to aid the quantification of fish locations.

All fish were manually tracked from video images relative to the bottom grid with positions by software Logger Pro 32. From the video recordings, the fish location and time spent in each cell of the grid (transit time) were determined and further analyzed in combination with the time-averaged 
hydraulic data (i.e., interpreted by the earlier defined Method I). The corresponding results derived from these tracks using Method I can be found in the work of Tan et al. [15].

\subsection{Numerical Model}

\subsubsection{Flow Equations}

The governing 3D unsteady Navier-Stokes equations in their compact form are:

$$
\nabla \bar{u}=0
$$

$$
\frac{\partial \bar{u}}{\partial t}+\bar{u} \times \nabla \bar{u}=-\frac{1}{\rho} \nabla p+v \nabla^{2} \bar{u}+\bar{f}_{b}
$$

where $u$ is velocity, $p$ is the pressure, $v$ is the kinematic viscosity, $\bar{f}_{b}$ is body forces (gravity and inertial force), and $t$ is the time.

\subsubsection{Turbulence Modeling}

Intermittently, all kinds of different scale fluctuations in vorticity, pressure, and velocity are the essential characteristics of the flow within the fishway. Thus, accurate modeling of these flow features is the basis of the successful design of a fishway with high performance.

Theoretically, Direct Numerical Simulations (DNS) is the best tool to resolve the turbulence, but it is too computationally demanding to be applied in a fishway flow. The Reynolds-Averaged Navier-Stokes (RANS) method and the Large-eddy Simulation (LES) model are the most appropriate options. Most earlier studies implemented RANS methods as the numerical tool for the 3D modeling of flow in the fishway [22-25] due to their extensive and robust applications in all kinds of flows in different industries, as well as representing a balance between computational cost and accuracy. However, a significant shortcoming in using RANS is that the approach only resolves mean flow characteristics, mainly omitting the more rapid turbulent structures in the flow. In contrast to RANS, LES includes large-scale turbulent flow structures. It provides time-resolved flow fields, including turbulent structures, which are the basis in the analysis of fishway performance by decoding the coupling of fish trajectories and the surrounding flow field. Due to the rapid development of computing capabilities, the LES model has become an available option for flow field simulations in the fishway study.

In the present study, the LES method was evaluated utilizing the Smagorinsky model [26]. In the Smagorinsky model, an effective viscosity is defined as:

$$
\begin{aligned}
& v_{e f f}=v+v_{s g s} \\
& v_{s g s}=C_{k} \Delta \sqrt{k}
\end{aligned}
$$

where $v_{\text {sgs }}$ is the subgrid-scale kinematic viscosity, $\Delta$ is the filter width, defined as the cube root of the volume of each cell, and $k$ is calculated from the velocity field by using Equation (5).

$$
\begin{gathered}
k=\frac{C_{k}}{C_{e}} \Delta^{2}|\bar{S}|^{2} \\
v_{s g s}=C_{k} \sqrt{\frac{C_{k}}{C_{e}}} \Delta^{2}|\bar{S}|=C_{s} \Delta^{2}|\bar{S}|
\end{gathered}
$$

Here, $|\bar{S}|=\sqrt{2 \times S_{i j} S_{i j}}$ and $S_{i j}$ is the rate of strain tensor of the large-scale or resolved velocity field. $C_{k}, C_{e}$, and $C_{s}$ are classical Smagorinsky constants; their values are 0.094, 1.048, and 0.168, respectively $[27,28]$. 


\subsubsection{Mesh and Boundary Conditions}

The final choice of mesh element size is highly case-specific; therefore, a mesh sensitivity analysis should be performed according to the American Society of Mechanical Engineers (ASME) criteria [29]. Regarding LES, it is essential to mention that the Smagorinsky method is an implicit approach, and thus the filter size will change with the selected grid size; as a result, there is no genuinely grid-independent solution. Thus, the selected LES method approaches DNS if the grid size is refined [30]. Klein \& Oertel [31] and Fuentes-Perez et al. [23] indicated that based on comparison of macro parameters, such as flow depths in pools or flow rate under various mesh resolutions, a mesh width of $3 \sim 4 \mathrm{~cm}$ is sufficient for practical use when a LES model is chosen. In the present study, a mesh width of $3 \mathrm{~cm}$ was selected. However, as a traditional practice, the outcome of $3 \mathrm{D}$ numerical models was additionally validated by comparing it with results from the experimental study.

The computation domain shown in Figure 2 is defined as the volume enclosed by the faces of the flume walls, baffles, water inlet cross-section, water outlet cross-section, flume bottom, and water surface. Because the head drop per pool was tiny, the water surface could be modeled as a smooth plane parallel to the flume bottom with zero shear stress. At the water inlet surface, a uniform velocity distribution was assigned, while at the water outlet surface, a pressure-outlet boundary condition was applied. A total of 65,098 hexahedral cells were used to mesh the domain. The calculation was initiated from a status of zero velocity everywhere in the domain. The timestep size was $0.01 \mathrm{~s}$. When the velocity at a predefined monitor point showed an oscillatory behaviour in time, the end of the simulation was reached. However, the simulation was extended for another $30 \mathrm{~s}$, in order to compare the results with the ADV measurements at least for a sampling period of $30 \mathrm{~s}$ at steady flow state.

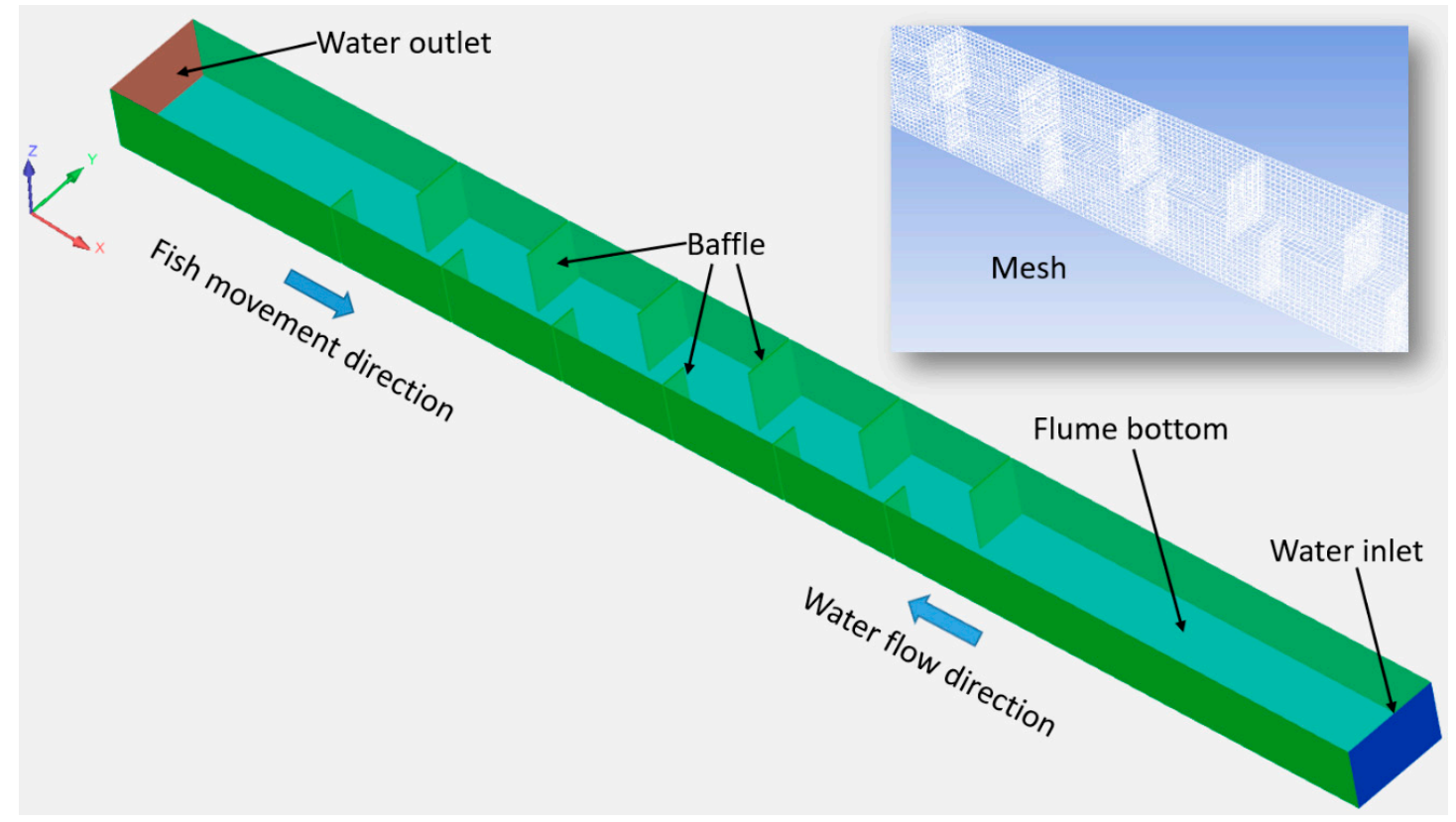

Figure 2. Computational domain and mesh.

\subsubsection{Validation}

\section{Velocity Contours}

Velocity contours measured by ADV are plotted in Figure 3a. At each ADV measurement, the transient velocities were acquired at $50 \mathrm{~Hz}$ for a sampling period of $30 \mathrm{~s}$. The contours from discrete ADV measurements are shown in Figure 3a. In contrast, the contours obtained by averaging the transient velocity during $30 \mathrm{~s}$ through the CFD technique are shown in Figure $3 \mathrm{~b}$. The flow pattern and velocity magnitude of the experimental and computational results were close. 
(a) Experiments

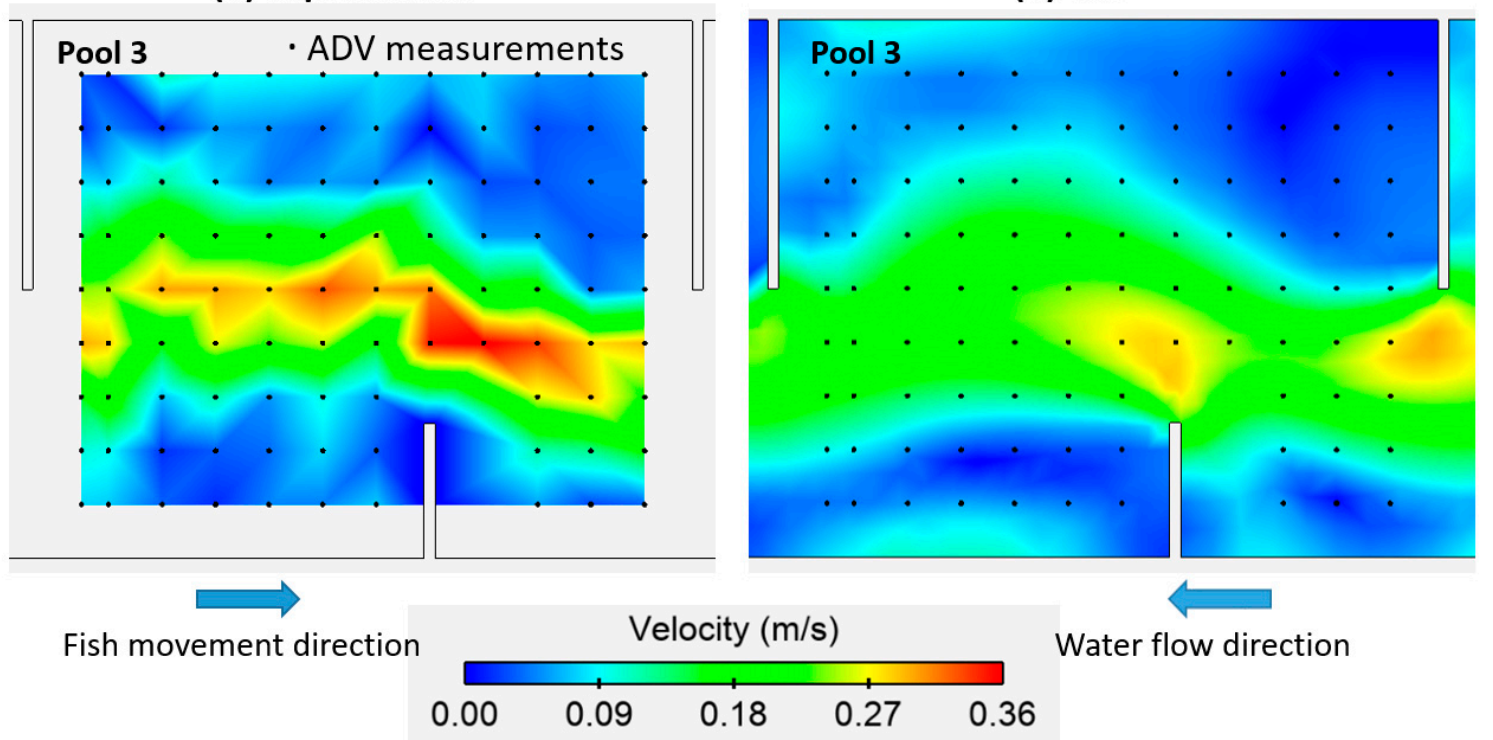

Figure 3. Velocity contours in the plane of $z=0.09 \mathrm{~m}$, black dots represent the ADV measurements. (a) Contours made from discrete ADV measurements. The region near the wall is blank because there were no measurements that could be used to interpolate contours. (b) Time-averaged velocity contours made from CFD transient simulation series. The length of the averaging period was $30 \mathrm{~s}$ and the time interval of the transient simulation series was $0.1 \mathrm{~s}$.

\section{Point Velocity}

Velocity components measured at points $A$ and $B$ are shown in Figure 4 . The fluctuation patterns and amplitudes of velocity signals in $x$ - and $z$-direction computed from CFD were very close to those measured by ADV.

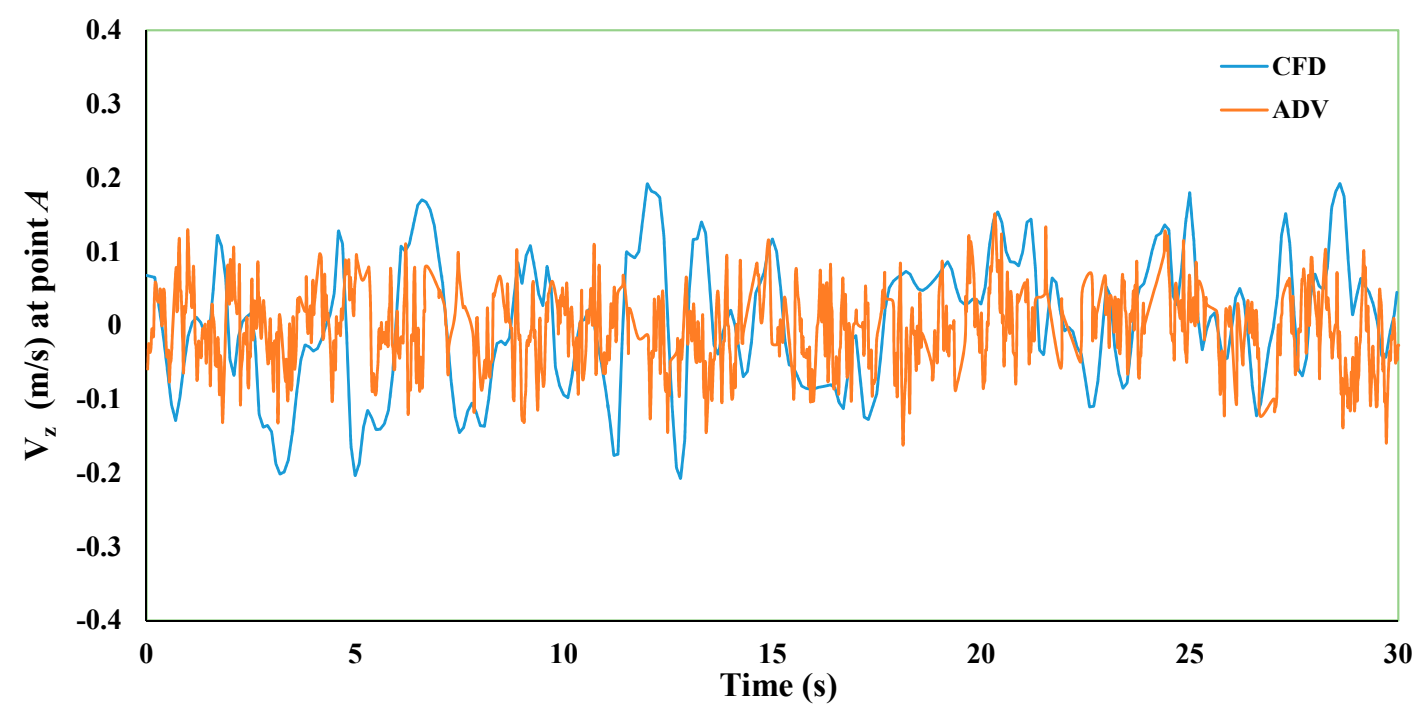

(a)

Figure 4. Cont. 


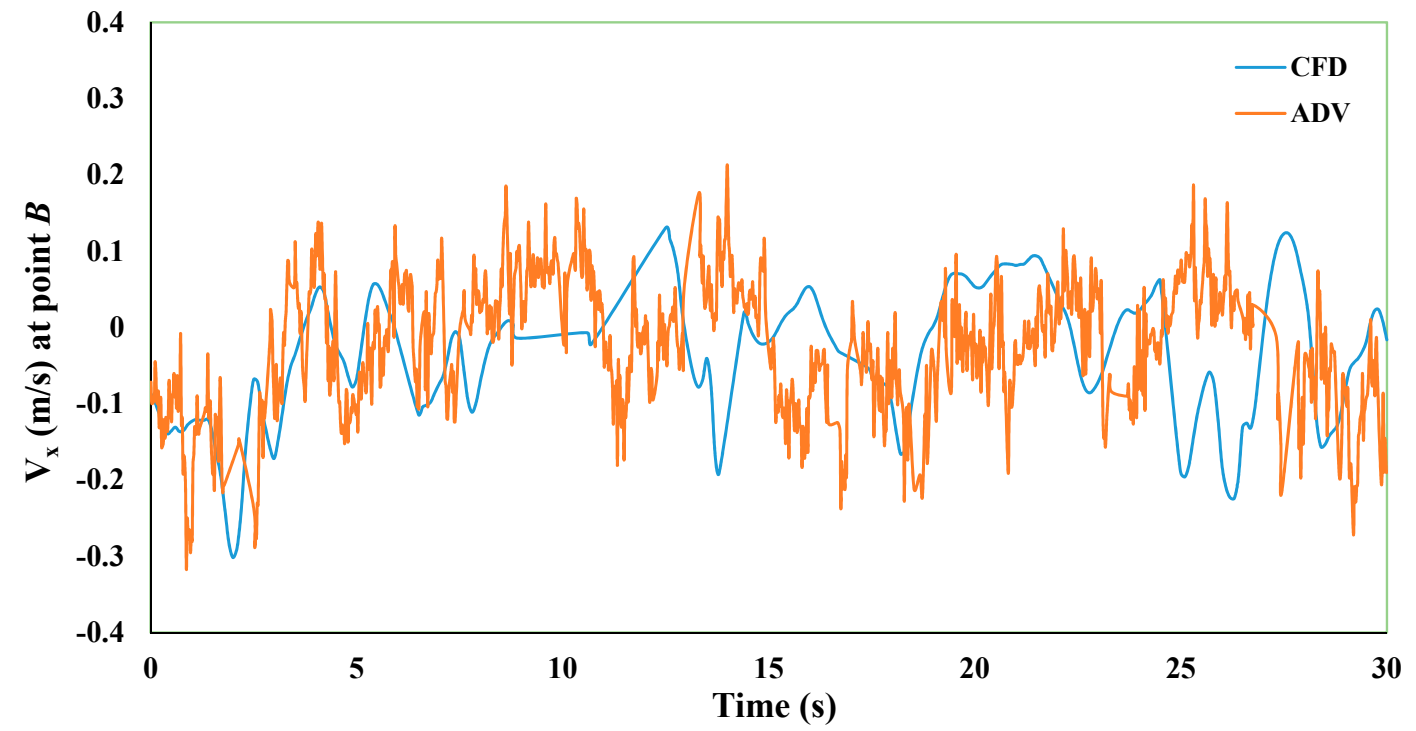

(b)

Figure 4. Velocity components signal $(50 \mathrm{~Hz})$ measured by ADV and simulated by the LES method in two spatially separated points $A$ and $B$ in Pool 3, the locations of $A$ and $B$ are shown in Figure 1c. (a) Variation of $V_{\mathrm{z}}$ (velocity component in the $z$-direction) along time axis for $30 \mathrm{~s}$ sampling time at point $A$. (b) Variation of $V_{\mathrm{x}}$ (velocity component in the $x$-direction) along the time axis for $30 \mathrm{~s}$ sampling time at point $B$.

Based on the above comparisons, we conclude that the simulation results are in overall good agreement with the experiments and could be used for further analysis.

\section{Results and Discussion}

\subsection{Mean Flow}

In the experiment, water depths were identical in the consecutive five pools. According to the definition suggested by Rajaratnam et al. [20] for the uniform flow in a fishway, we could regard the flow as "steady and uniform"; however, if we carefully inspect the velocity contours shown in Figure 5, the assertion of uniform flow is not accurate.

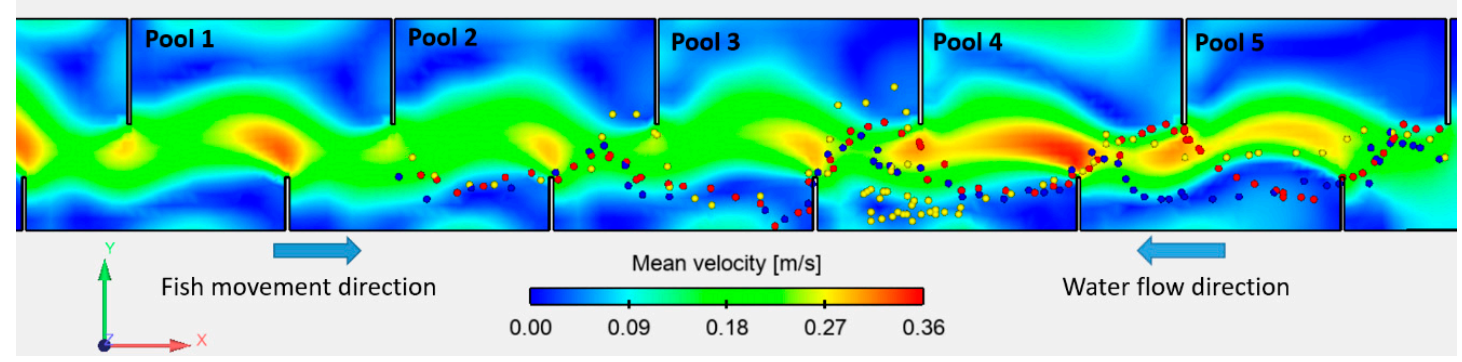

Figure 5. The randomness of fish trajectories observed during the fish tracking in an experimental vertical slot fishway. The dots represent the live fish trajectories. Each color represents one individual fish. The background is the mean velocity contours produced at the plane at $0.3 h_{0}$ from the fishway bottom ( $h_{0}$ is the water depth in the fishway).

In Figure 5, the flow structures at the entrance and exit are quite different from those in the middle part of the fishway, although all the pools have the same water depth. In many fishway studies, researchers often adopt intermediate ponds as the representative case to describe the flow structures, thereby ignoring the differences between the flow at the inlet and outlet. This overlook 
will discount the application effects of the fishway, since fish will take different paths in response to varying flow patterns.

\subsection{Velocity Barrier}

It is generally believed that the high velocity at the vertical slot of the fishway is always an upstream obstacle, which is observed from the time-averaged speed. If we see the velocity at a slot from the perspective of the transient flow field, the flow barrier at the slot does not always exist. At certain moments, the flow rate at the vertical slot decreases to zero, as shown in Figure 6. Even at certain moments, as shown in Figure 7, the direction of local water flow is in line with the ascending path of the fish, which can also be partially verified from the velocity fluctuations seen in Figure $4 b$, i.e., the alternating sign of the velocity component.

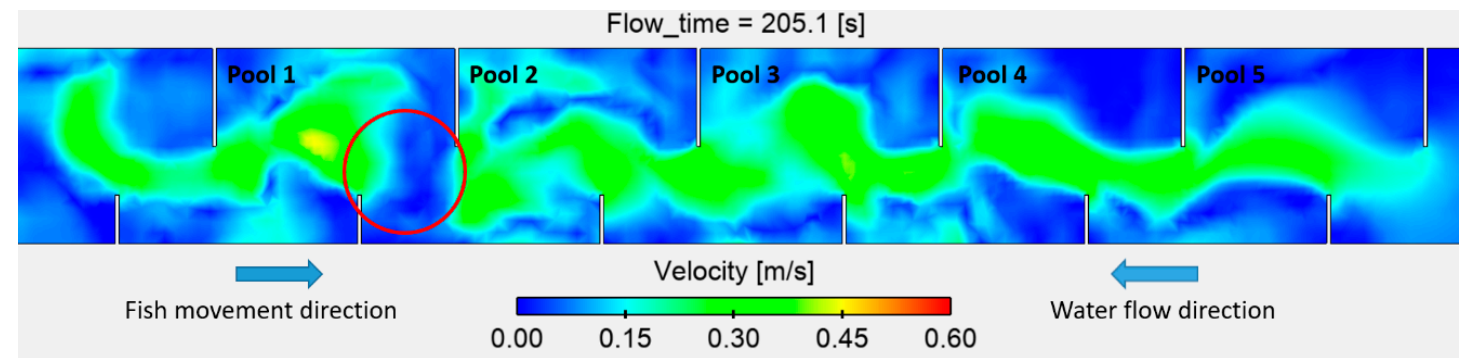

Figure 6. At some instances, low-velocity areas appear in the fish passage, which the fish can use to aid their ascent. For example, at time 205.1 s, the circled area has zero velocity. For an upstream fish, the velocity barrier is temporarily removed, and the fish can move laterally in this area.

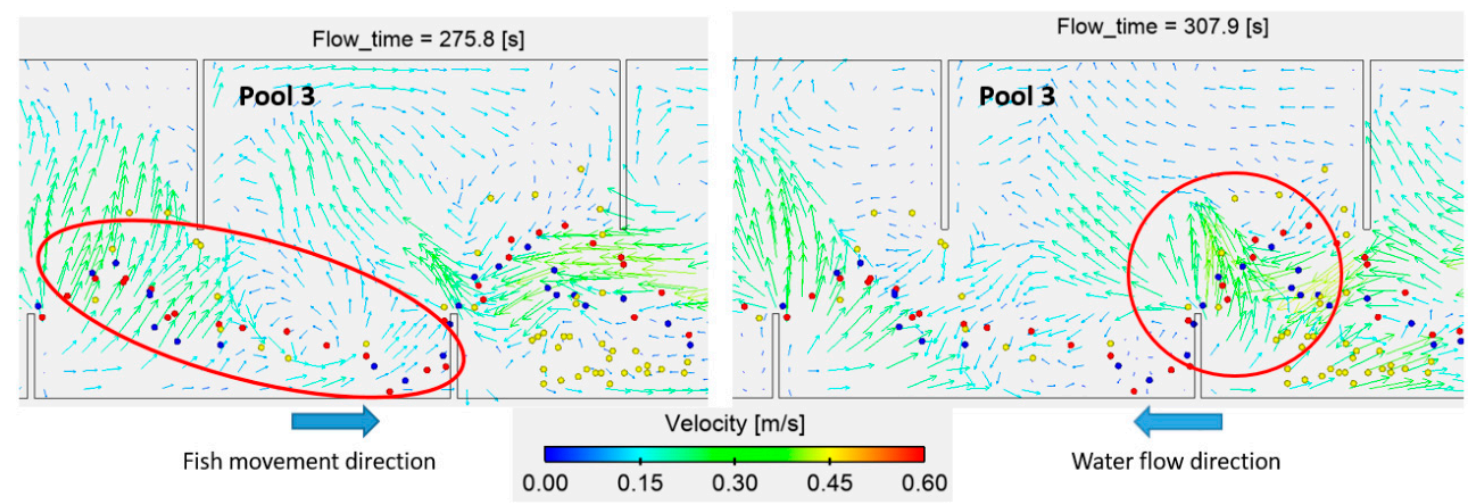

Figure 7. At some moments, the local flow direction could point in the fish ascending direction, e.g., in the area circled, the fish may utilize the flow to "drift" themselves to the upstream locations without consuming much energy.

The appearance of a "velocity barrier" varies over time, which may be an explanation of the phenomenon that fish occasionally are wandering in a pool for quite a long time, and then suddenly swim through consecutive pools in a row. Fish swimming behind the baffles may not always be resting to recover. They could simply wait for the opportunities (windows) of "velocity barrier disappearance", and then they could take the lucky moments to easier swim upstream.

\subsection{Trajectory of Fish}

In Figure 5, although the fish paths were limited in some particular areas in the plane, the trajectories show a characteristic randomness. One explanation for this kind of randomness, as Farnsworth et al. [32] pointed out, is that randomness is a fundamental feature of animal choices. Additionally, we can see the typical practice of superposing the recorded live fish trajectories on the mean flow fields. Meanwhile, in Figure 8, another method of superposing the recorded live fish 
trajectories on the transient velocity contours obtained by CFD (specifically LES here) can be seen. Both approaches are not ideal analysis methods because both of them neglect the fact that live fish trajectories primarily originate under unique turbulent flow conditions with specific vortical structures at particular time series. In other words, an ideal analysis of fish behavior strictly requires that a live fish trajectory and the corresponding flow environment should be recorded at exactly the same time.
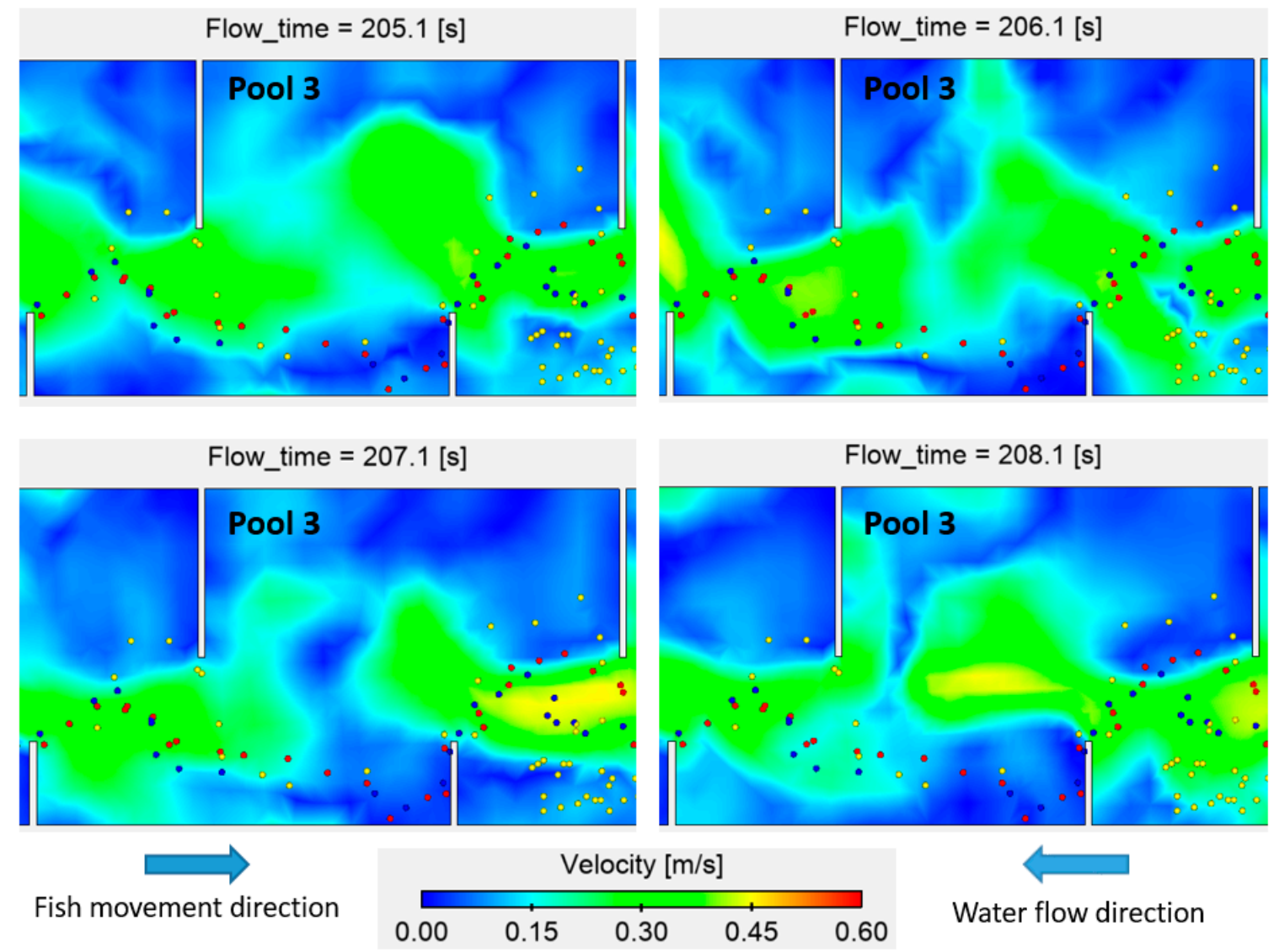

Water flow direction

Figure 8. Velocity contours at different moments of time (205.1 s, $206.1 \mathrm{~s}, 207.1 \mathrm{~s}, 208.1 \mathrm{~s})$ in the plane at $z=0.09 \mathrm{~m}$ in pool 3. The dots represent the recorded live fish trajectories, separate colors for each individual fish.

According to the random characteristics of the flow field seen in Figures 7 and 8, the randomness of fish movement is likely to be the superposition of the randomness of the flow field and the randomness of movement selection of aquatic animals. Further similar figures showing random trajectories can be found in the works of Smith et al. [33], Rodriguez et al. [34,35], Puertas et al. [36], and Goettel et al. [3].

The discussion about the randomness of fish trajectories has practical implications for fish path modeling. For example, if someone wants to simulate the fish paths based on superposing the recorded live fish trajectories on the mean flow fields, a workaround is to introduce some random functions or constants, such as advocated by Goodwin et al. [10] and Gao et al. [12]. However, the random functions or constants seriously depend on the specific cases, limiting their universality in practical applications.

\subsection{New Requirement for Experiments}

Method II conquers the shortcomings of Method I by simultaneously obtaining precise fish positions and the corresponding flow field around the fish. Furthermore, muscle activity (oxygen consumption) could be additionally measured at the same time, to understand the energetic demands (swimming costs) of fish under different turbulent flow conditions. Theoretically, this is an ideal method to describe the fish movement. However, there are still many limitations to the application of this method. For example, the illumination range of the laser sheet is narrow, there is a shadow on the 
backlit side of the illuminated object, how to use a full set of measuring devices outdoor, whether the laser sheet will affect the swimming behaviour and physiological indexes of fish. Those may be the reasons why studies published in the literature using Method II are often limited to simple flow fields. For example, research relevant to the motion of fish in a vortex street generated by a single blunt body with simple geometry. Applications in fishways are rarely to be found.

\subsection{How to Use CFD Tools}

Fast Fourier Transform (FFT) converts data from the temporal domain to the frequency domain, which allows a direct comparison of different temporal series in the frequency domain. FFT is of particular interest in turbulence, since an exact repetition of two temporal series representing the same turbulent flow phenomenon is impossible. So, we may speculate that FFT might possibly provide a new way to analyze and model the fishway flow field in the frequency domain. For example, a specific physical flow field, from which a live fish trajectory was obtained, may have highly similar spectral features to a computed flow field obtained by modern CFD. If we could obtain a comparatively stable relationship between the live fish trajectory and the spectrum of the physical flow field, then we can use the computed flow field to replace the physical flow field. This can be justified, since the calculated flow field and the real flow field have similar spectral characteristics in the frequency domain. If this way is feasible, then we have a new design framework to extend experimental or in situ study results to other scenarios.

In Figure 9, the normalized Power Spectrum Density (PSD) of the velocity components at point $A$ and $B$ are shown, respectively. When the frequency is larger than $1 \sim 2 \mathrm{~Hz}$, the PSD curves computed by the numerical and experimental method are not overlapped anymore. Because LES filters out high-frequency oscillations according to the used cell size (Equation (4)), this model shows difficulty in estimating the high-frequency oscillations. However, this can be remedied by adjusting and refining the cell size. Fish are sensitive to those vortices with a size larger or comparable to their body length (corresponding to a relatively low frequency), as shown in the work of Tritico and Cotel [7]. The small eddies do not need to be precisely computed. Coincidently, in LES, those tiny eddies (corresponding to high frequencies) are also modeled or filtered out without computing.

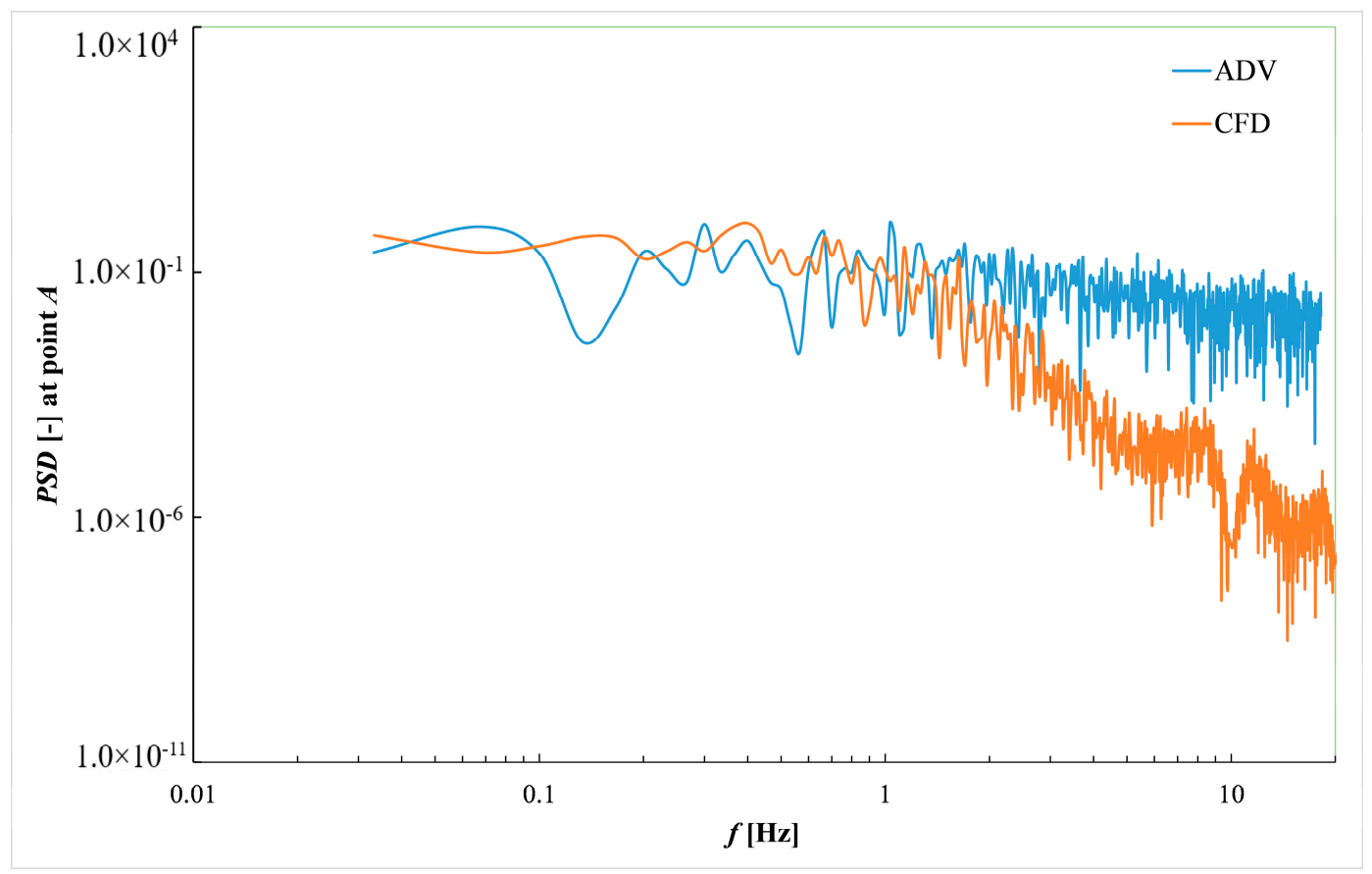

(a)

Figure 9. Cont. 


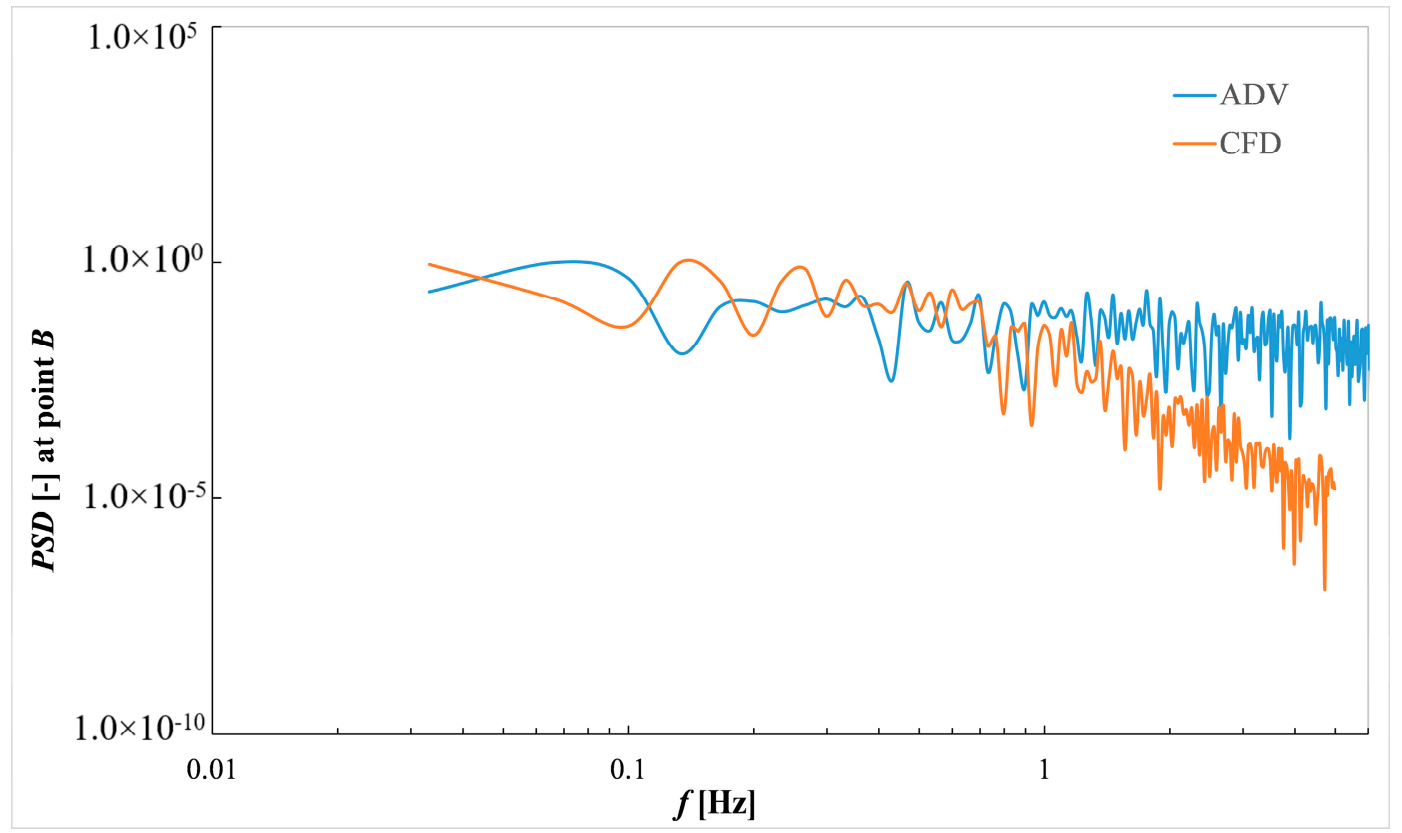

(b)

Figure 9. Power spectral density (PSD) of (a) $V_{\mathrm{z}}$ at point $A$, and (b) $V_{\mathrm{x}}$ at point $B$.

In this paper, 65,098 hexahedral cells were used to mesh the computational flow domain; this provided a relatively cheap cost compared to currently available computing conditions. Nevertheless, it is yet to be determined which frequencies or ranges of spectrum are relevant for fish, which is only obtained in experiments.

With the development of the CFD technique, for the sake of convenience, time discretization is usually dynamically controlled using the Courant number to guarantee computational stability. Still, the time step is also a sensitive parameter for fish movement description. Details of fish movement will likely be lost if a more significant time step is chosen, especially when they swim in specific flow patterns with a particular spatial-temporal scale. However, a smaller time step will consume more computer resources (computer time and storage) and usually produce an overwhelming amount of data; if we cannot find an effective way to analyze such huge data sets, the data will be useless to us. So, an information process technique relevant to fish trajectory modeling is urgently needed in this field.

\section{Conclusions}

Reduced fish mortality (or improved fishway passage efficiency) is the end objective of almost all attempts to model fish trajectories. In the work of Roscoe et al. [37], migration failure occurred in all sections of the migration route, including the fishway, which supports the hypothesis that dam/fishway passage has post-passage consequences on survival. So, the precise description of fish trajectories is a necessary and powerful tool to help us understand how fish suffer in this kind of hydraulic structure and why the paths are like that. However, an accurate description of a trajectory means not only obtaining precise fish positions, but also corresponding measurements of the flow field around the fish.

In this paper, we have demonstrated that methods based only on time-averaged point values (by ADV measurements or numerical simulation) are a "have no alternative" way due to the limitations of currently available technology in this field. Readers should therefore adopt conclusions derived from this method in literature cautiously. It seems that "water preferences" should best be explained as that the fish utilized some flow structures along the trajectories to help themselves swim through the vertical slot fishway. A local transient planar or volumetric measurement of the flow field with simultaneous recording of fish movement is an urgent and critical demand. However, many challenges still exist in this technique. A CFD technique might provide a by-pass tool to understand the mechanisms of 
why fish trajectories have an appearance like that. Converting data from the temporal domain to the frequency domain and determining which frequencies or spectra are relevant for fish may be a new approach in CFD to conquer the puzzle of how to reproduce the basic features of the target fish trajectory in different flow scenarios. However, the first step is to make sure the relationship between the frequency and the fish trajectory still starts from the challenging experiments using Method II.

The species selected here was merely an easily acquirable representative of fish, which was used to help demonstrate that the simultaneous measurements of fish movement and the flow field around them are necessary for fish behavior studies. Therefore, the statements of these thoughts do not depend on a specific species. In other words, using another species to repeat the experiment will only enrich the proofs of our thoughts stated in this study.

Fish in a more natural status could make a more realistic response to hydraulic stimuli and produce a more realistic fish trajectory. Careful biological and environmental considerations for specimens should be included in this experiment, such as the light/dark cycle control and water composition. In the current study, we focused on evaluating the reasonability of the way of a superposing. A not so perfect (not the most natural) fish movement will not affect the conclusions of this study. However, in future more intensive research, the complete biologically and environmentally experimental conditions must be taken into account, in order to reproduce a more realistic fish trajectory in indoor experiments.

Despite the above difficulties, the future of these approaches is promising, because, for a given fish species, their responses to specific stimuli or flow structures are unchanged. Once researchers grasp that constant information, we obtain a new general design tool, no matter how the flow conditions change with the variations in hydrology, geometry, or operation of fishway running. We just let the virtual fish swim in the numerical flow field. The trajectories will tell us which design or running conditions are better than the others.

Author Contributions: G.Z. conceived the idea, developed the model, data analysis and wrote the manuscript; H.I.A. and Z.Z. supervised the modelling and writing process. All authors have read and agreed to the published version of the manuscript.

Funding: This work is supported by the Open Research Fund of State Key Laboratory of Simulation and Regulation of Water Cycle in River Basin (China Institute of Water Resources and Hydropower Research) (IWHR-SKL-201616); Nantong Science and Technology Development Funds (JC2018143); National Key R\&D Program of China (2016YFC0402405); National Science and Technology Major Project of Water Pollution Control and Prevention of China (2012ZX07201-006); Science and Technology Key Project of Jiangxi Province (KT201508) and Hunan Provincial Natural Science Foundation (Grant No. 2017JJ2296).

Acknowledgments: We appreciate the anonymous reviewers' helpful suggestions.

Conflicts of Interest: The authors declare no conflict of interest.

Ethics Statement: This study was conducted in strict accordance with the laws governing animal experimentation in China. The China Three Gorges University approved the protocol. All efforts were made to minimize suffering.

\section{References}

1. Lacey, R.W.J.; Neary, V.S.; Liao, J.C.; Enders, E.C.; Tritico, H.M. The IPOS Framework: Linking Fish Swimming Performance in Altered Flows from Laboratory Experiments to Rivers. River Res. Appl. 2012, 28, 429-443. [CrossRef]

2. Silva, A.T.; Santos, J.M.; Ferreira, M.T.; Pinheiro, A.N.; Katopodis, C. Effects of Water Velocity and Turbulence on the Behaviour of Iberian Barbel (Luciobarbus bocagei, Steindachner 1864) in an Experimental Pool-Type Fishway. River Res. Appl. 2011, 27, 360-373. [CrossRef]

3. Goettel, M.T.; Atkinson, J.F.; Bennett, S.J. Behavior of western blacknose dace in a turbulence modified flow field. Ecol. Eng. 2015, 74, 230-240. [CrossRef]

4. Tan, J.; Gao, Z.; Dai, H.; Yang, Z.; Shi, X. Effects of turbulence and velocity on the movement behaviour of bighead carp (Hypophthalmichthys nobilis) in an experimental vertical slot fishway. Ecol. Eng. 2019, 127, 363-374. [CrossRef]

5. Liao, J.C.; Beal, D.N.; Lauder, G.V.; Triantafyllou, S.M. Fish Exploiting Vortices Decrease Muscle Activity. Science 2003, 302, 1566-1569. [CrossRef] [PubMed] 
6. Liao, J.C.; Beal, D.N.; Lauder, G.V.; Triantafyllou, S.M. The Karman gait: Novel body kinematics of rainbow trout swimming in a vortex street. J. Exp. Biol. 2003, 206, 1059-1073. [CrossRef]

7. Tritico, H.M.; Cotel, A.J. The effects of turbulent eddies on the stability and critical swimming speed of creek chub (Semotilus atromaculatus). J. Exp. Boil. 2010, 213, 2284-2293. [CrossRef]

8. Liao, J.C.; Akanyeti, O. Fish Swimming in a Karman Vortex Street: Kinematics, Sensory Biology and Energetics. Mar. Technol. Soc. J. 2017, 51, 48-55. [CrossRef]

9. Weber, L.J.; Goodwin, R.A.; Li, S.; Nestler, J.M.; Anderson, J.J. Application of an Eulerian-Lagrangian-Agent method (ELAM) to rank alternative designs of a juvenile fish passage facility. J. Hydroinform. 2006, 8, 271-295. [CrossRef]

10. Goodwin, R.A.; Nestler, J.M.; Anderson, J.J.; Weber, L.J.; Loucks, D.P. Forecasting 3-D fish movement behavior using a Eulerian-Lagrangian-agent method (ELAM). Ecol. Model. 2006, 192, 197-223. [CrossRef]

11. Goodwin, R.A.; Politano, M.; Garvin, J.W.; Nestler, J.M.; Hay, D.; Anderson, J.J.; Weber, L.J.; Dimperio, E.; Smith, D.L.; Timko, M. Fish navigation of large dams emerges from their modulation of flow field experience. Proc. Natl. Acad. Sci. USA 2014, 111, 5277-5282. [CrossRef] [PubMed]

12. Gao, Z.; Andersson, H.I.; Dai, H.C.; Jiang, F.J.; Zhao, L.H. A new Eulerian-Lagrangian agent method to model fish paths in a vertical slot fishway. Ecol. Eng. 2016, 88, 217-225. [CrossRef]

13. Zielinski, D.P.; Voller, V.R.; Sorensen, P.W. A physiologically inspired agent-based approach to model upstream passage of invasive fish at a lock-and-dam. Ecol. Model. 2018, 382, 18-32. [CrossRef]

14. Jager, H.I.; DeAngelis, D.L. The confluences of ideas leading to, and the flow of ideas emerging from, individual-based modeling of riverine fishes. Ecol. Model. 2018, 384, 341-352. [CrossRef]

15. Tan, J.J.; Tao, L.; Gao, Z.; Dai, H.C.; Shi, X.T. Modeling Fish Movement Trajectories in Relation to Hydraulic Response Relationships in an Experimental Fishway. Water 2018, 10, 1511. [CrossRef]

16. LaBone, E.; Justic, D.; Rose, K.; Wang, L.; Huang, H. Modeling Fish Movement in 3-D in the Gulf of Mexico Hypoxic Zone. Estuaries Coasts 2019, 42, 1662-1685. [CrossRef]

17. Gilmanov, A.; Zielinski, D.; Voller, V.; Sorensen, P. The Effect of Modifying a CFD-AB Approach on Fish Passage through a Model Hydraulic Dam. Water 2019, 11, 1176. [CrossRef]

18. Padgett, T.E.; Thomas, R.E.; Borman, D.J.; Mould, D.C. Individual-based model of juvenile eel movement parametrized with computational fluid dynamics-derived flow fields informs improved fish pass design. R. Soc. Open Sci. 2020, 7, 191505. [CrossRef]

19. Shi, X.; Jin, Z.; Liu, Y.; Hu, X.; Tan, J.; Chen, Q.; Huang, Y.; Liu, D.; Wang, Y.; Gu, X. Can age-0 Silver Carp cross laboratory waterfalls by leaping? Limnologica 2018, 69, 67-71. [CrossRef]

20. Rajaratnam, N.; Vinne, G.V.d.; Katopodis, C. Hydraulics of Vertical Slot Fishways. J. Hydraul. Eng. 1986, 112, 909-927. [CrossRef]

21. Ke, S.F.; Li, Z.M.; Jiang, Z.W.; Goerig, E.; Kynard, B.; Liu, D.F.; Shi, X.T. Effect of a vertical half cylinder on swimming of silver carp, Hypophthalmichthys molitrix: Implications for microhabitat restoration and fishway design. River Res. Appl. 2019, 35, 436-441. [CrossRef]

22. Quaresma, A.L.; Romao, F.; Branco, P.; Ferreira, M.T.; Pinheiro, A.N. Multi slot versus single slot pool-type fishways: A modelling approach to compare hydrodynamics. Ecol. Eng. 2018, 122, 197-206. [CrossRef]

23. Fuentes-Perez, J.F.; Silva, A.T.; Tuhtan, J.A.; Garcia-Vega, A.; Carbonell-Baeza, R.; Musall, M.; Kruusmaa, M. 3D modelling of non-uniform and turbulent flow in vertical slot fishways. Environ. Model. Softw. 2018, 99, 156-169. [CrossRef]

24. An, R.D.; Li, J.; Liang, R.F.; Tuo, Y.C. Three-dimensional simulation and experimental study for optimizing a vertical slot fishway. J. Hydro-Environ. Res. 2016, 12, 119-129. [CrossRef]

25. Lindberg, D.E.; Leonardsson, K.; Andersson, A.G.; Lundstrom, T.S.; Lundqvist, H. Methods for locating the proper position of a planned fishway entrance near a hydropower tailrace. Limnologica 2013, 43, 339-347. [CrossRef]

26. Smagorinsky, J. General circulation experiments with the primitive Equations: I. The basic experiment. Mon. Weather Rev. 1963, 91, 99-164. [CrossRef]

27. Deardorff, J.W. A numerical study of three-dimensional turbulent channel flow at large Reynolds numbers. J. Fluid Mech. 1970, 41, 453-480. [CrossRef]

28. Lilly, D.K. The Representation of Small Scale Turbulence in Numerical Simulation Experiments; National Center for Atmospheric Research: Boulder, CO, USA, 1966. 
29. Celik, I.B.; Ghia, U.; Roache, P.J.; Freitas, C.J. Procedure for estimation and reporting of uncertainty due to discretization in CFD applications. J. Fluids Eng. Trans. ASME 2008, 130, 4.

30. Celik, I.; Klein, M.; Janicka, J. Assessment measures for engineering LES applications. J. Fluids Eng. Trans. ASME 2009, 131, 10. [CrossRef]

31. Klein, J.; Oertel, M. Vertical Slot Fishway: Evaluation of Numerical Model Quality. In Proceedings of the 6th IAHR IJREWHS 2016, Lübeck, Germany, 30 May-1 June 2016.

32. Farnsworth, K.D.; Beecham, J.A. How Do Grazers Achieve Their Distribution? A Continuum of Models from Random Diffusion to the Ideal Free Distribution Using Biased Random Walks. Am. Nat. 1999, 153, 509-526. [CrossRef]

33. Smith, D.L.; Brannon, E.L.; Odeh, M. Response of Juvenile Rainbow Trout to Turbulence Produced by Prismatoidal Shapes. Trans. Am. Fish. Soc. 2005, 134, 741-753. [CrossRef]

34. Rodriguez, A.; Bermudez, M.; Rabunal, J.R.; Puertas, J.; Dorado, J.; Pena, L.; Balairon, L. Optical Fish Trajectory Measurement in Fishways through Computer Vision and Artificial Neural Networks. J. Comput. Civ. Eng. 2011, 25, 291-301. [CrossRef]

35. Rodriguez, A.; Bermudez, M.; Rabunal, J.R.; Puertas, J. Fish tracking in vertical slot fishways using computer vision techniques. J. Hydroinform. 2015, 17, 275-292. [CrossRef]

36. Puertas, J.; Cea, L.; Bermudez, M.; Pena, L.; Rodriguez, A.; Rabunal, J.R.; Balairon, L.; Lara, A.; Aramburu, E. Computer application for the analysis and design of vertical slot fishways in accordance with the requirements of the target species. Ecol. Eng. 2012, 48, 51-60. [CrossRef]

37. Roscoe, D.W.; Hinch, S.G.; Cooke, S.J.; Patterson, D.A. Fishway Passage and Post-Passage Mortality of Up-River Migrating Sockeye Salmon in the Seton River, British Columbia. River Res. Appl. 2011, 27, 693-705. [CrossRef]

(C) 2020 by the authors. Licensee MDPI, Basel, Switzerland. This article is an open access article distributed under the terms and conditions of the Creative Commons Attribution (CC BY) license (http://creativecommons.org/licenses/by/4.0/). 